\title{
ANALYSIS OF BIODEGRABILITY OF DEGRADABLE/BIODEGRADABLE PLASTIC MATERIAL IN CONTROLLED COMPOSTING ENVIRONMENT
}

\author{
Dana Adamcová1, Magdalena Daria Vaverková', Tomáš Mašíček', Eliška Břoušková \\ 1 Department of Applied and Landscape Ecology, Faculty of AgriSciences, Mendel University in Brno, \\ Zemědělská 1, 61300 Brno, Czech Republic \\ 2 Department of Morphology, Physiology and Animal Genetics, Faculty of AgriSciences, Mendel University in \\ Brno, Zemědělská 1, 61300 Brno, Czech Republic, e-mail: magda.vaverkova@uake.cz
}

Received: 2016.06 .23 Accepted: 2016.08 .08 Published: 2016.09.20

\begin{abstract}
We have obtained eight degradable/biodegradable materials based on starch (certified compostable), sample 4-7, HDPE mixed with totally degradable plastic additive (TDPA), sample 2 and polyethylene with the addition of pro-oxidant additive $\left(\mathrm{d}_{2} \mathrm{w}\right)$, sample 1. Composition of sample 3 has not been reported. The materials have been tested as to the rate and character of their degradability/biodegradability in controlled composting conditions. Experiment explored also the effect of degradation/biodegradation of plastic bags on compost quality. The material of the original samples was subjected to assessment using the Nicolet 6700 FT-IR spectrometer, the outcome thereof was obtaining infrared spectra of the samples. For further specification the original samples were tested using the thermogravimetrical analysis. The texture of the foils at different stages of degradation is presented in the Scanning Electron Microscope (SEM) photographs. Plastic bags certified as compostable have degraded in laboratory conditions and their degradation had no impact on the quality and features of compost. Selected samples $(4,6)$ showed significant erosion on surface when subjected to the SEM analysis. Samples labeled (by their producers) as 100\% degradable (samples 1, 2,3 ) did not show any visual signs of degradation and the process of degradation had no impact on the quality and features of compost. Only one of the samples (sample 1) showed certain erosion of surface when submitted for the SEM analysis.
\end{abstract}

Keywords: degradation, controlled environment, thermogravimetrical analysis, SEM photographs

\section{INTRODUCTION}

Plastic is a relatively cheap, durable and versatile material. Plastic products have brought benefits to society in terms of economic activity, jobs and quality of life. Plastics can even help reduce energy consumption and greenhouse gas emissions in many circumstances, even in some packaging applications when compared to the alternatives [Mudgal et al. 2011]. However, plastic waste also imposes negative environmental externalities. It is usually non-biodegradable and therefore can remain as waste in the environment for a very long time; it may pose risks to human health as well as the environment; and it can be difficult to reuse and/or recycle in practice [Mudgal et al. 2011].

In 2009, annual plastics production was 230 million tons globally, of which about 60 million tons were produced in Europe. Polyethylene was the most abundant of the produced plastics. The share of bioplastics, including both bio-based plastics and biodegradable plastics, was only $0.1-0.2$ per cent of the total amount of plastics produced in the European Union. However, the market share of bioplastics is increasing rapidly [Mudgal et al. 2011]. For the last decade the technology of plastic production has considerably changed thanks to the use of different type fillers. Thus obtained composites have improved the properties of plastics and 
extended the range of their use so that the natural materials have been gradually phased out. Their increasing use has been accompanied by the increasing pollution of the natural environment with hardly degradable waste (underground and surface waters, soil, dumping grounds) [Kozłowski 1998, Domka et al. 2009]. Recycling is only a partial solution, so attempts have been made to improve the degradability of plastics in natural conditions [Domka et al. 2009, Pieluchowski and Puszyński 1998]. The biodegradable materials are produced on the basis of biodegradable polymers obtained from reproducing raw materials, such as starch, or from petrochemical materials. Such polymers can be used separately or in combination with resins or other additions. Plastics based on starch are called second generation. They have become very popular in the packaging industry (produced in the form of foils, thermosetting trays and containers, disposable cups), the cosmetics industry, sports and logistics [Domka et al. 2009].

We have obtained degradable/biodegradable materials based on starch, HDPE mixed with totally degradable plastic additive and polyethylene with the addition of pro-oxidant additive. The materials have been tested as to the rate and character of their degradability/biodegradability in controlled composting conditions [Vaverková et al. 2012]. The texture of the foils at different stages of degradation is presented in the Scanning Electron Microscope (SEM) photographs. Research results are in detail described in "Study of the biodegrability of degradable/biodegradable plastic material in a controlled composting environment" [Vaverková et al. 2012]. Experiment explored also the effect of degradation/biodegradation of biologically decomposable plastic bags on compost quality described in "The effect of biodegradation/degradation of degradable plastic material on compost quality” [Adamcová et al. 2013].

\section{EXPERIMENTAL PROCEDURES}

\section{Bioplastic materials}

The investigated degradable/biodegradable materials were obtained from chain stores in the Czech Republic and Poland. Seven kinds of degradable/biodegradable plastic bags were used in this study and cellulose filter paper as a positive control. One of them was a plastic bag made of HDPE and mixed with totally degradable plastic additive (TDPA additive). Another was a plastic bag made of polyethylene with the addition of pro-oxidant additive ( $\mathrm{d}_{2} \mathrm{w}$ additive). One was labeled as $100 \%$ degradable within various periods of time, from three months up to three years, and four were certified compostable. The amounts of synthetic waste and plastic pieces placed in each reactor are listed in Table 1.

\section{Disintegration tests}

The degree of disintegration of the pieces obtained was evaluated following modified version of ČSN EN 14806 Norm "Packaging - Preliminary evaluation of the disintegration of the packaging materials under simulated composting conditions in a laboratory scale test" and a modified version of ČSN EN ISO 20200 "Plastics Determination of the degree of disintegration of plastic materials under simulated composting conditions in a laboratory-scale test" (ISO 20200:2004). Apart from disintegration/biodegradation, the laboratory experiment explored also the effect of degradation/biodegradation of biologically decomposable plastic bags on compost quality. The compost quality was assessed in the accredited laboratory ČIA no. 1147 (LABTECH s.r.o.) in Brno. The assessment entailed analyses of selected physical and chemical characteristics of composts pursuant to the standard ČSN

Table 1. Amounts of synthetic waste and plastic pieces placed in each reactor

\begin{tabular}{|c|l|l|c|c|}
\hline \multicolumn{1}{|c|}{ Type } & \multicolumn{1}{|c|}{ Description } & $\mathrm{M}_{i}{ }^{*}$ sample $(\mathrm{g})$ & $\mathrm{m}$ substrate $(\mathrm{g})$ \\
\hline 1 & N/A & BIO-D Plast & 3.5 & 1000 \\
\hline 2 & HDPE+TDPA & $100 \%$ degradable & 7.02 & 1000 \\
\hline 3 & N/A & $100 \%$ degradable & 7.03 & 1000 \\
\hline 4 & Starch & Compostable 7P0147 & 7.01 & 1000 \\
\hline 5 & Starch and Polycaprolactone & OK Compost AIB VINCOTTE & 7.02 & 1000 \\
\hline 6 & N/A & Compostable 7P0202 & 7.01 & 1000 \\
\hline 7 & Natural material & Compostable 7P0073 & 7.02 & 1000 \\
\hline 8 & Cellulose (blank) & - & 7.02 & 1000 \\
\hline
\end{tabular}

* $\mathrm{M}_{i}-$ initial dry mass of plastic material. 
465735 Industrial composts [Adamcová et al. 2013]. The experiment setup is described in article "The effect of biodegradation/degradation of degradable plastic material on compost quality" [Adamcová et al. 2013].

\section{RESULTS AND DISCUSSION}

The operational parameters showed that the test was valid. The cellulose filter paper completely degraded after 10 days, implying that it was fully biodegraded and that the conditions required for biodegradation to occur in a sampling environment were present. No breakthrough in disintegration was observed for samples 1,2 , and 3 during 12 weeks of composting. The test material still remained completely intact. The samples did not show any significant biodegradation or any visual changes and were not broken into smaller pieces or easily crumbled when touched. The surface was smooth, and there were no pinholes observed on the surface after the test. Sample 2 showed no decrease in color intensity, the pigment was still rich. Samples 1 and 3 showed a visible change in pigmentation [Vaverková et al. 2012, Adamcová et al. 2013].

It was found that the weight loss of the degraded material strongly depends on the specific kind of biodegradable plastic. The degradation of the certified compostable plastic bags (samples 4, 5,6 , and 7) proceeded very well. After 6 weeks of composting in the laboratory-scale test, the different test materials seemed to completely disappear. This was confirmed at the end of the test. No single piece of sample 5 or 7 could have been retrieved at the end of the test. The mass of sample
4 was measured to be $0.03 \mathrm{~g}$ after finishing the test, while the mass of sample 6 was measured to be $0.009 \mathrm{~g}$ (Figure 1).

Four certified compostable plastic bags showed a complete level of degradation during the 12-week composting laboratory-scale test. Test material 1, 2, and 3 remained completely intact at the end of the test. The experiment did not yield the anticipated results, despite the fact that many studies have confirmed the biodegradability of the plastics samples [Chiellini et al. 2003, Jakubowicz et al. 2006, Billingham et al. 2002, Raninger et al. 2002, Rojas and Greene 2007].

After finishing the test a chemical analysis of the substrate was carried out. The aim of the chemical analysis was to find out the influence of the qualitative parameters of the substrate after the biodegradation process of the samples. The compost samples were analyzed in an accredited laboratory; evaluated parameters were as follows: DM of the original sample, DM of the laboratory sample $\left(105^{\circ} \mathrm{C}\right)$, exchangeable soil reaction $\left(\mathrm{CaCl}_{2}\right)$, Melich III - contents of available nutrients (calcium, magnesium, potassium, total phosphorus), total contents of arsenic, cadmium, chromium, copper, molybdenum, nickel, lead, zinc and mercury [Adamcová et al. 2013]. All eight samples met parameters stipulated for Class II. Seven samples of the eight met parameters stipulated in the standard ČSN 465735 for Class I. The analysis showed that the parameters conclusive for the compost quality did not exceed limits stipulated in the standard. The samples had no influence on compost characteristics: strength, content of water and salt, $\mathrm{pH}$ value, content of nutrients or proportion of organic substances; other components of the compost remained unchanged.

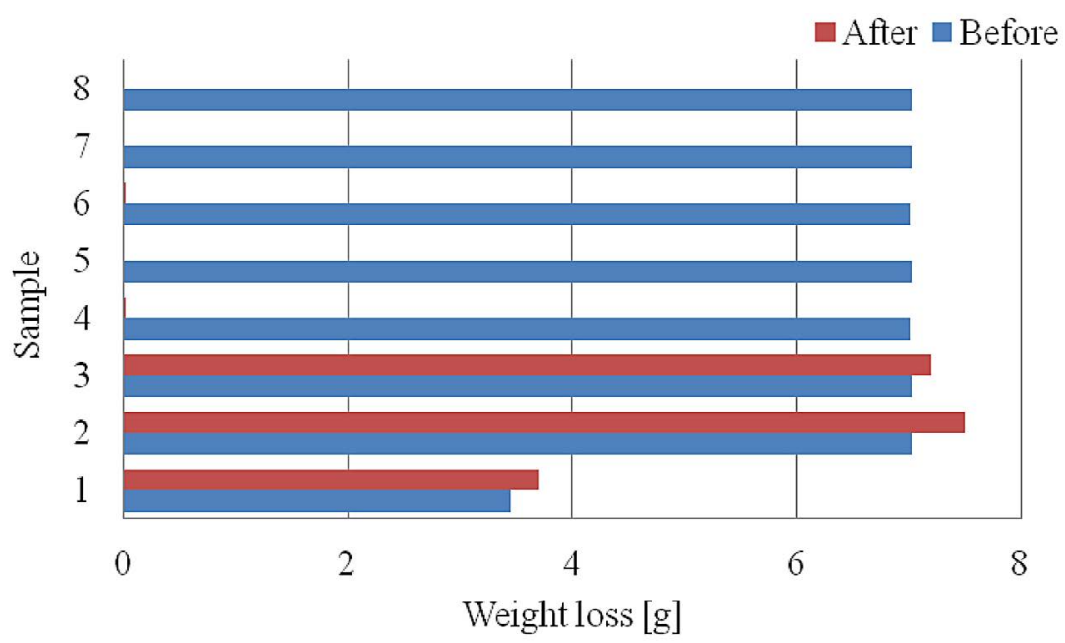

Figure 1. The weight losses of samples before and after degradation 
Optical changes of the compost did not occur either [Adamcová et al. 2013].

On the grounds of an absence of producer's statement regarding material composition of the plastic bags (sample 1, 2, 3, 4, 6) which were only provided with advertisement labeling, an analysis of selected samples was carried out, based on the results of previous experiments.

In total eight samples were tested in laboratory conditions. Since samples 5 and 7 degraded very well (completely disappear), it was impossible to submit them for subsequent analysis. Sample 8 was a control sample, namely cellulose; neither this sample was subjected to further analysis. After the experiment in laboratory conditions (controlled environment) was completed, the samples of remainder materials and samples of the original materials were subjected to the following analysis. It specifically concerned the below listed samples (Table 2).

Table 2. Sample types

\begin{tabular}{|c|c|}
\hline Sample & Type \\
\hline 1 & N/A* \\
\hline 2 & HDPE+TDPA \\
\hline 3 & N/A \\
\hline 4 & Starch \\
\hline 6 & N/A \\
\hline
\end{tabular}

* N/A - not available.

The material of the original samples $(1,2,3$, 4 and 6) was subjected to assessment using the Nicolet 6700 FT-IR spectrometer, the outcome thereof was obtaining infrared spectra of the samples. For further specification the original samples 2 and 3 were tested using the thermogravimetrical analysis (hereinafter „TGA”). In addition, all original samples as well as samples obtained after the end of the experiment $(1,2,3$, 4 and 6) were submitted for Scanning Electron Microscopy (“SEM").

\section{The evaluation of samples by means of the Nicolet 6700 FT-IR spectrometer}

The original samples 1, 2, 3, 4 and 6 were assessed using the Nicolet 6700 FT-IR spectrometer. The samples were compared with reference foil polyethylene and reference foil polyethylene $+10 \%$ of starch. Parameters of the analysis were as follows: GladiATR measuring technique, $4 \mathrm{~cm}^{-1}$ resolution, number of accumulations 64 , Happ - Genzel apozidation. Based on the measurement, the IR spectra for each respective analyzed sample were determined as presented in the graphs below (Figures 2-8).

IR spectrum defined as P217 corresponds to sample 1. IR spectrum defined as P219 corresponds to sample 2. IR spectrum defined as P218 corresponds to sample 3. IR spectrum defined as P216 corresponds to sample 4. IR spectrum defined as P220 corresponds to sample 6. IR spectrum defined as P225 is a reference sample polyethylene $+10 \%$ of starch and IR spectrum defined as P224 is reference sample polyethylene.

The original materials of samples 1,2, 3 show in IR spectra absorbance units that are typical for polyethylene which contains additives, yet non identified ones. IR spectrum of sample 4 contains (besides additives) units typical for polyvinylalcohol.

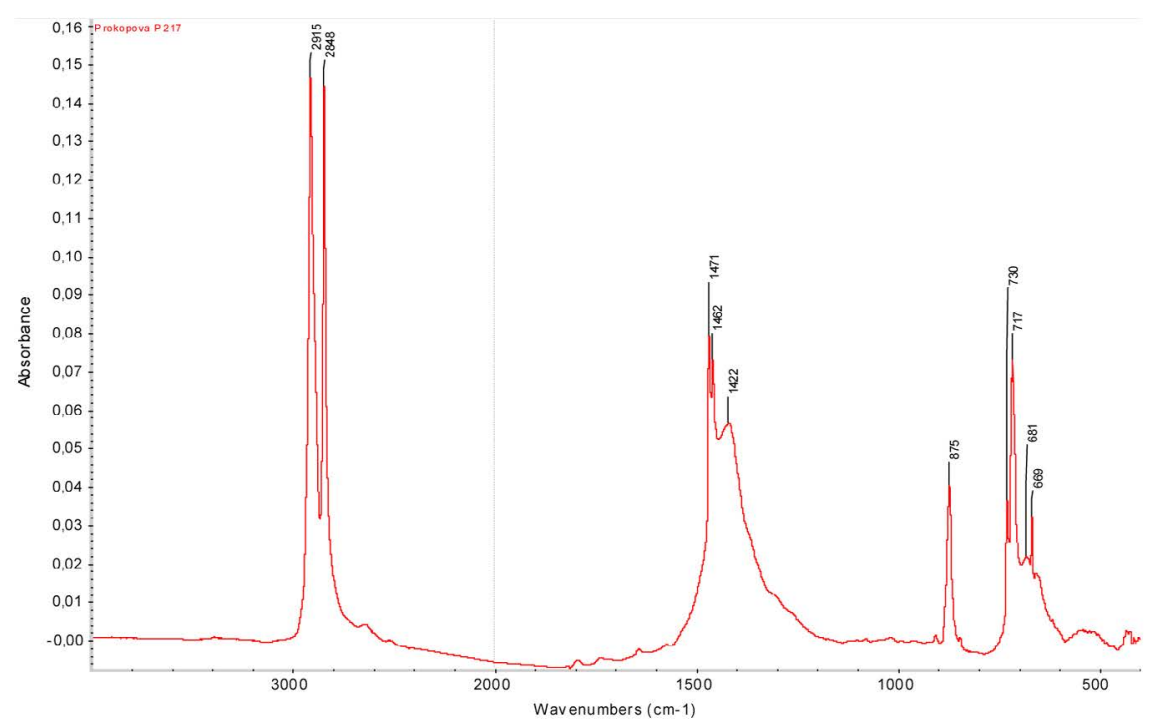

Figure 2. IR spectrum sample 1 


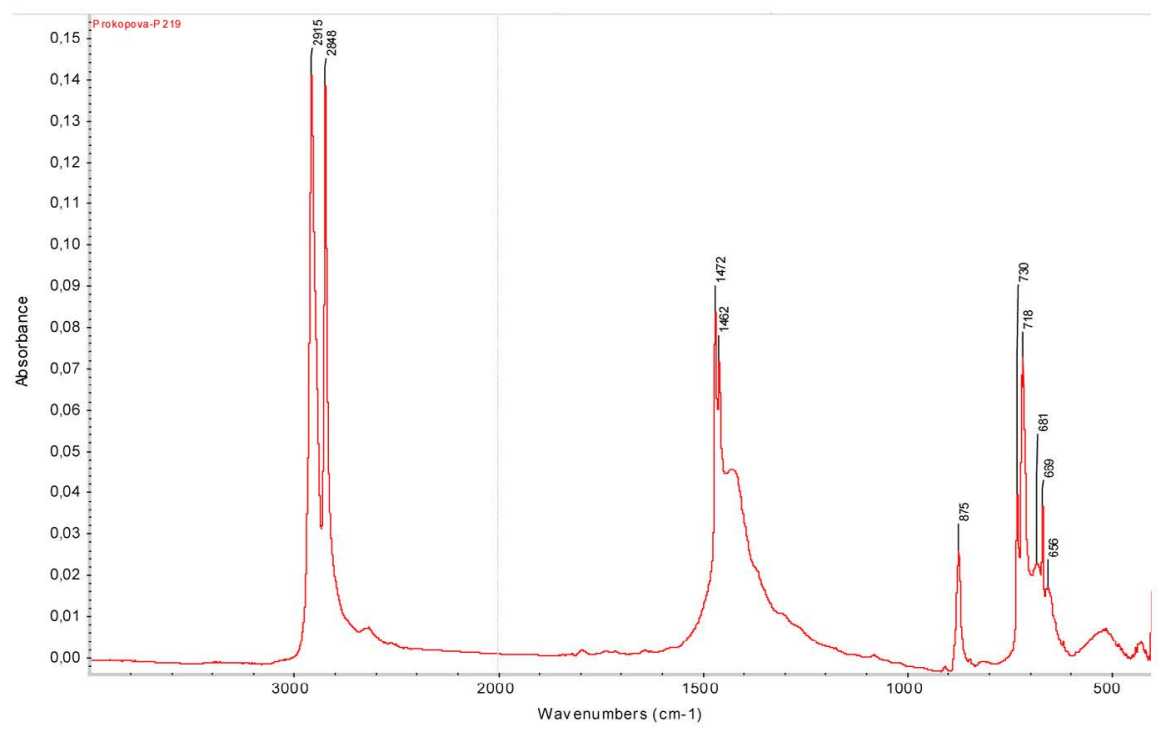

Figure 3. IR spectrum sample 2

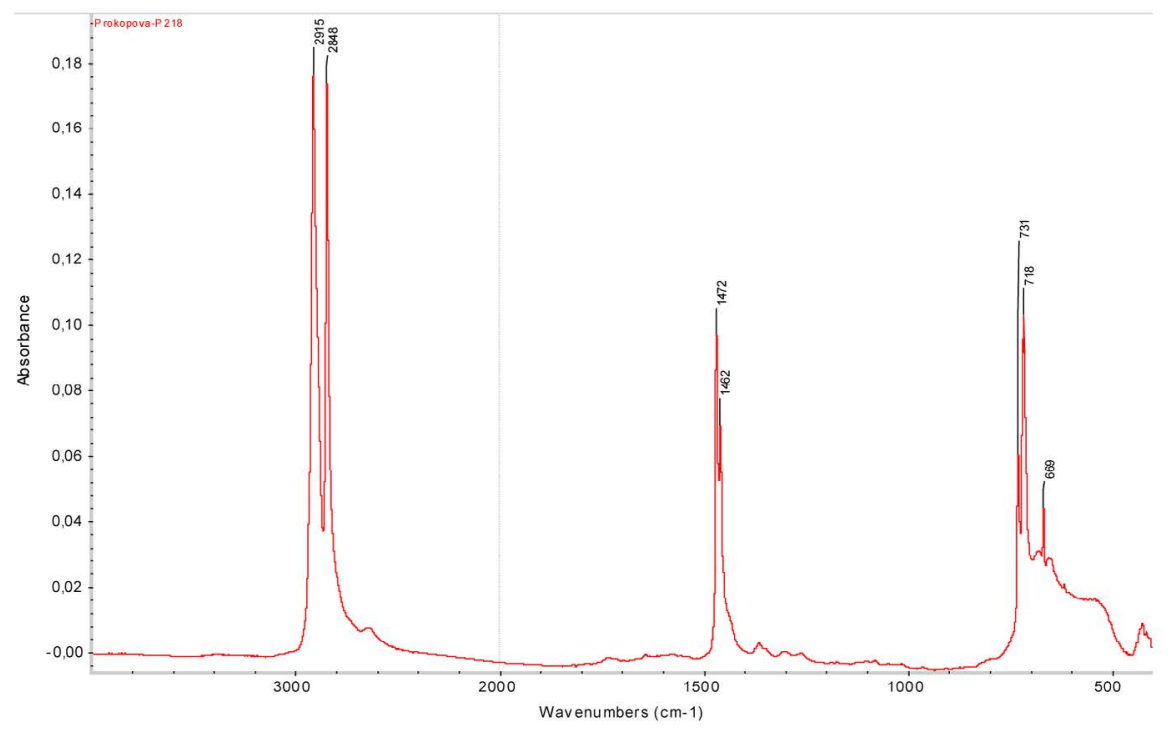

Figure 4. IR spectrum sample 3

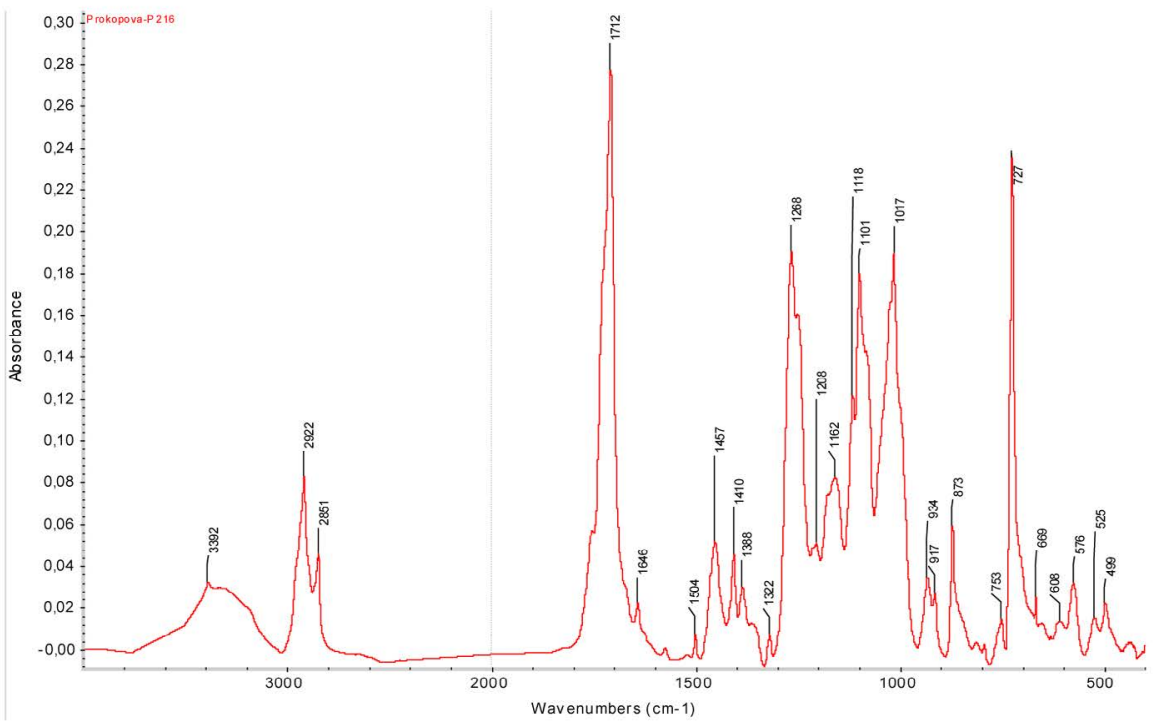

Figure 5. IR spectrum sample 4 


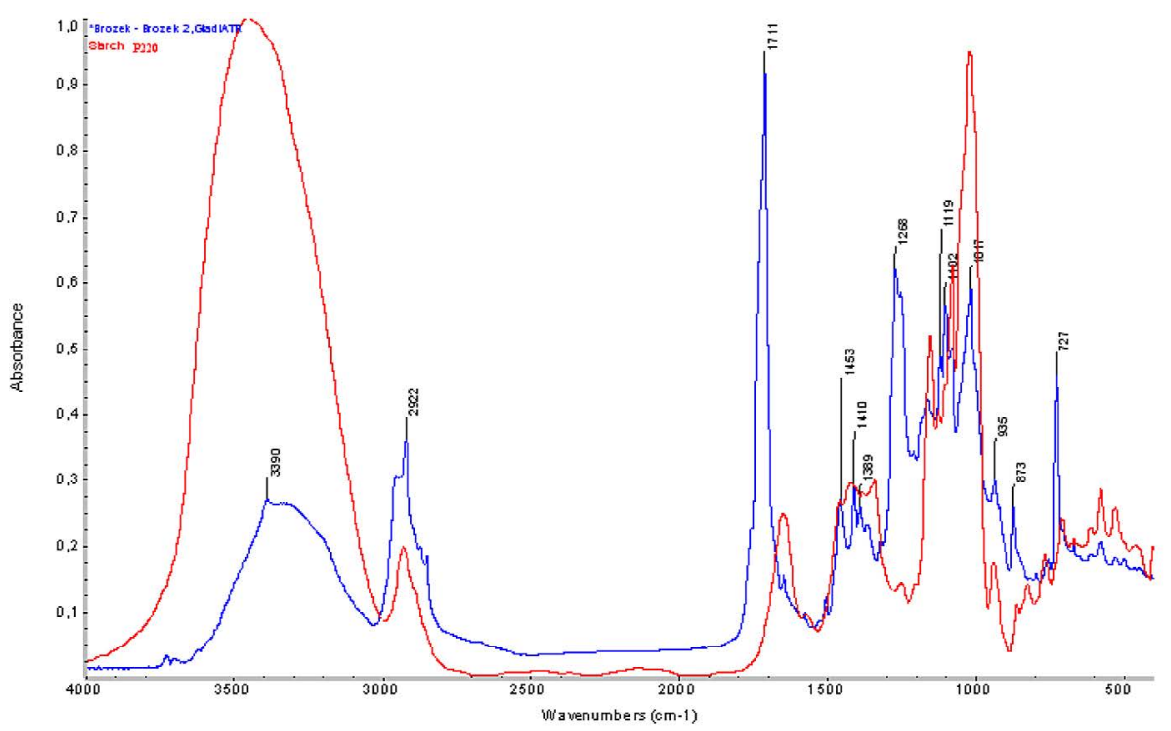

Figure 6. IR spectrum sample 6

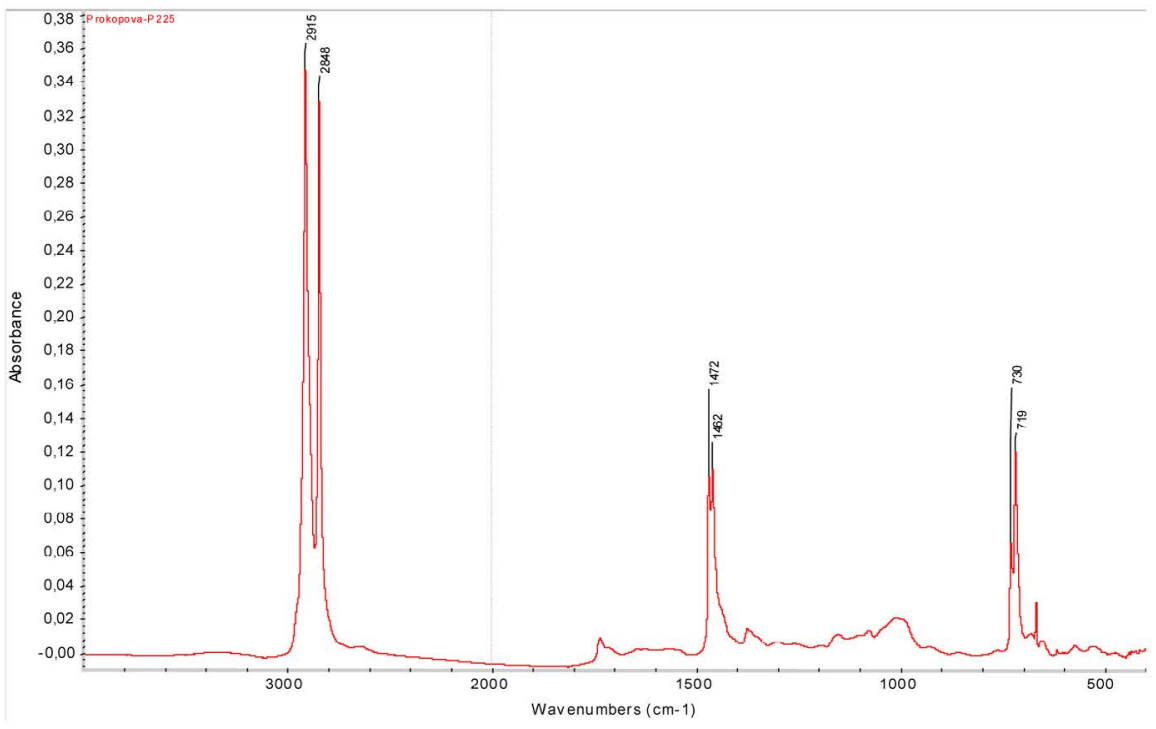

Figure 7. IR spectrum reference sample polyethylene $+10 \%$ of starch

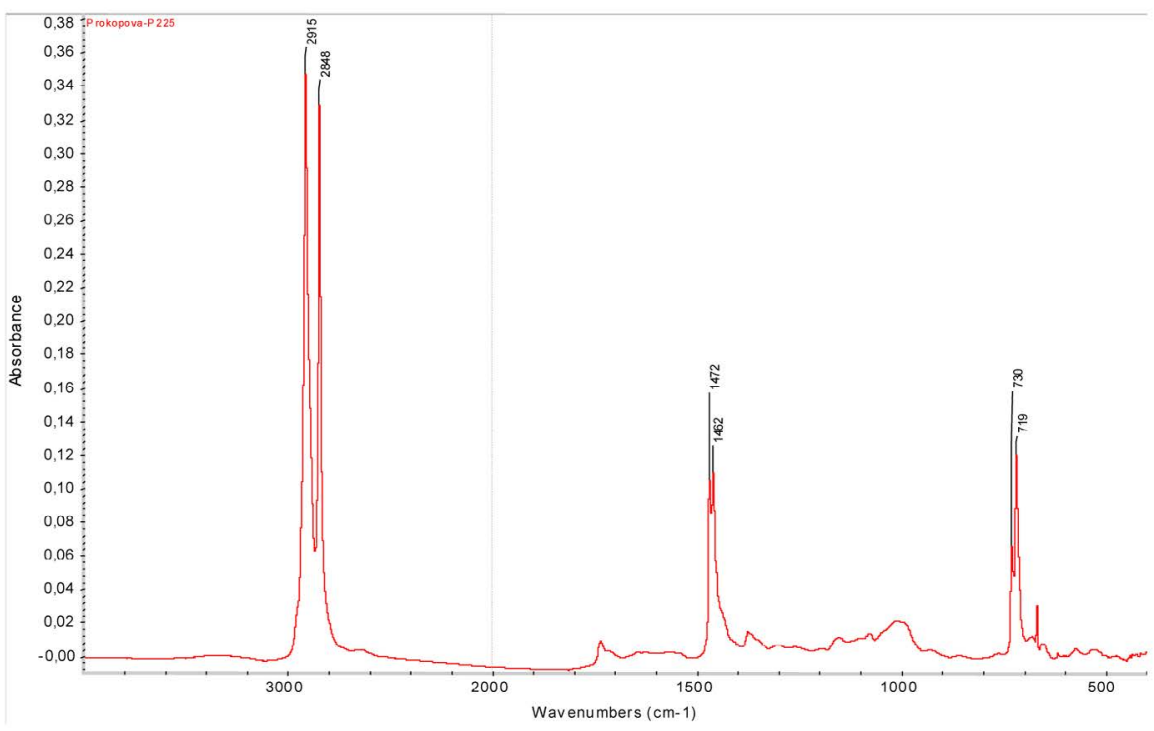

Figure 8. IR spectrum reference sample polyethylene 


\section{The evaluation of samples by means of thermogravimetric analysis}

Based on the statement made by producers of samples 2 and 3 that the materials are $100 \%$ degradable, these samples were subjected to Thermogravimetric Analysis. The results for samples 2 and 3 are illustrated in Figures 9 and 10.

According to the TGA sample 2 contains at $600{ }^{\circ} \mathrm{C}$ about $10 \%$ of nonincinerable remainder and when heated up to $700{ }^{\circ} \mathrm{C}$, it declines to $6,4 \%$.

Sample 3 reaches by $600{ }^{\circ} \mathrm{C} 1,6 \%$ of nonincinerable remainder, which remains constant.

\section{The evaluation of samples by means of electron micsroscopy}

The samples were subsequently submitted for Scanning Electron Microscopy (SEM). The experiment involved images of both the original samples and samples that underwent composting process. Each sample was depicted at $1000 \times$ and $2000 \times$ magnification. The illustrations are presented in Figures 11-30.

The figures from Scanning Electron Microscopy (SEM) illustrate that the structure of surface of the original plastic bags (defined as "(a)") com-

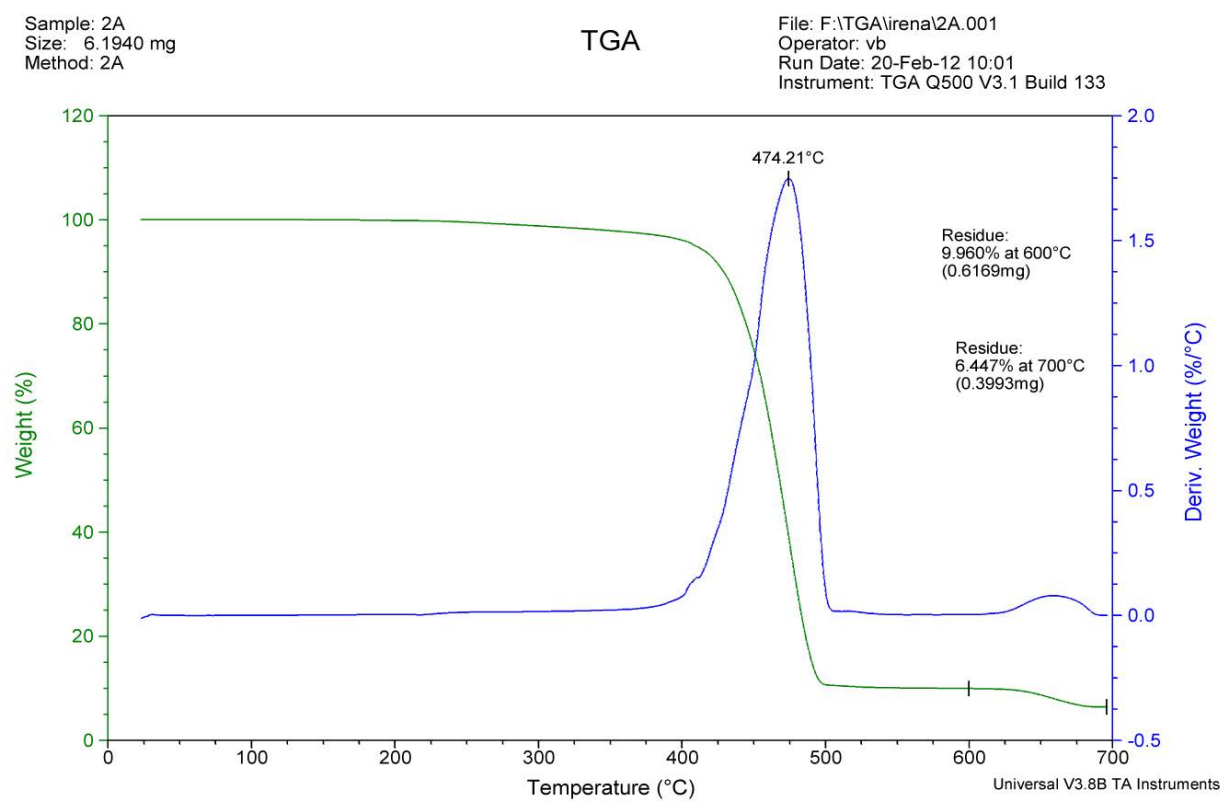

Figure 9. Spectrum TGA sample 2

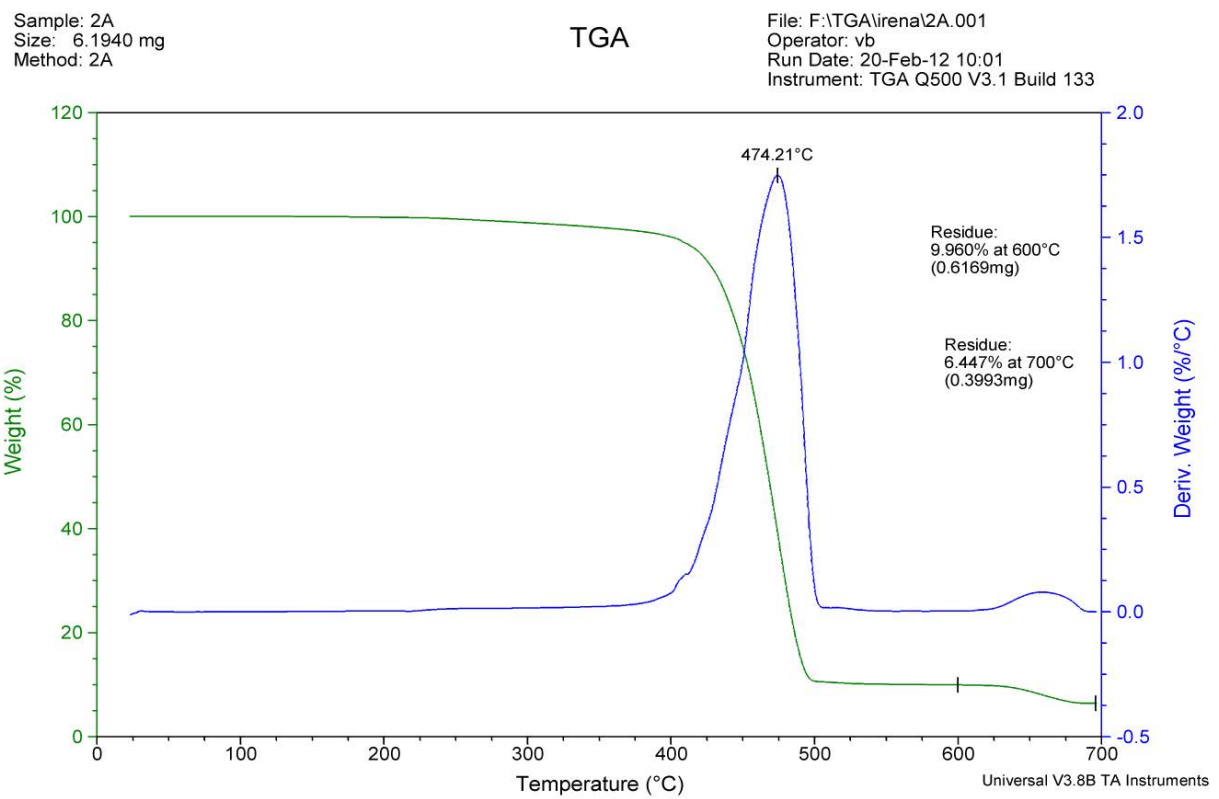

Figure 10. Spectrum TGA sample 3 


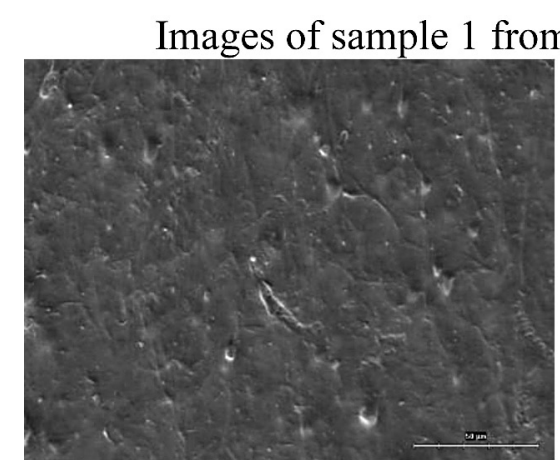

Figure 11. Sample 1a - 1000×

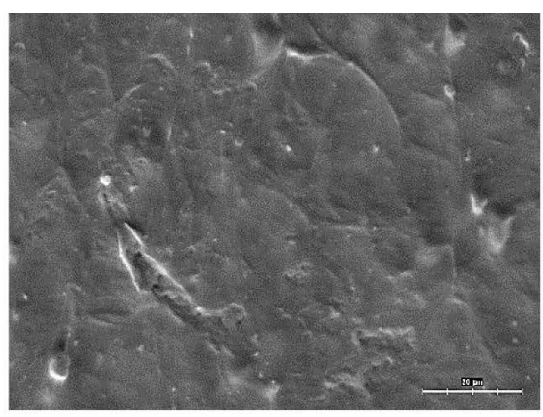

Figure 13. Sample 1a - 2000x

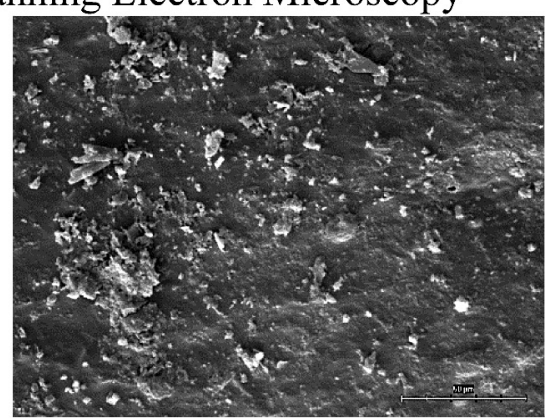

Figure 12. Sample 1b - 1000×

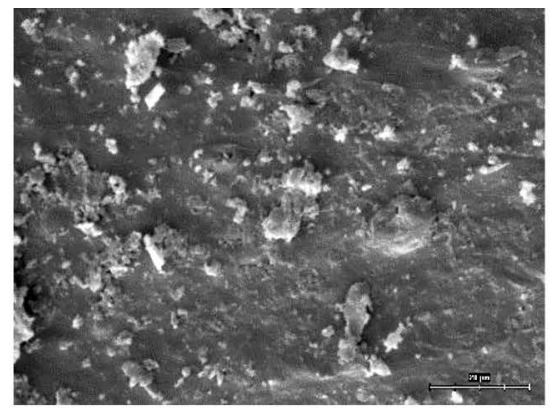

Figure 14. Sample 1b - 2000×

Images of sample 2 from Scanning Electron Microscopy

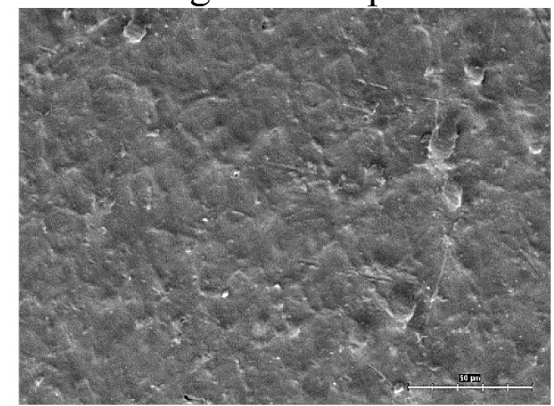

Figure 15. Sample $2 \mathrm{a}-1000 \times$

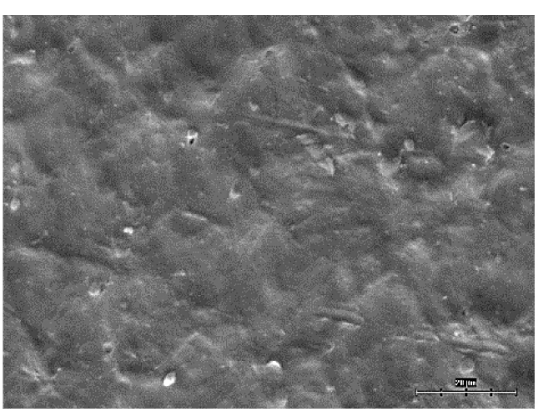

Figure 17. Sample $2 \mathrm{a}-2000 \times$

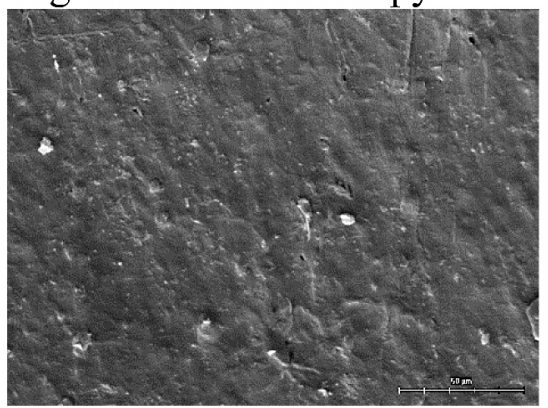

Figure 16. Sample 2b - 1000×

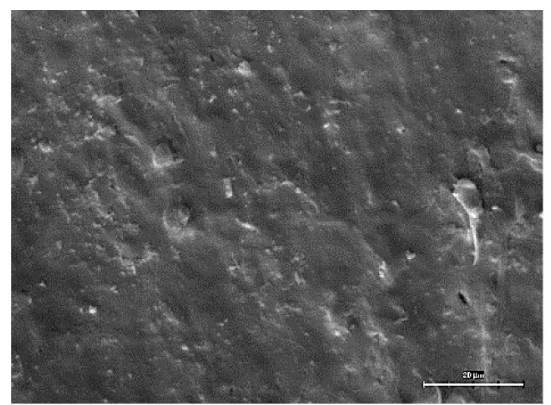

Figure 18. Sample 2b - 2000×

Images of sample 3 from Scanning Electron Microscopy

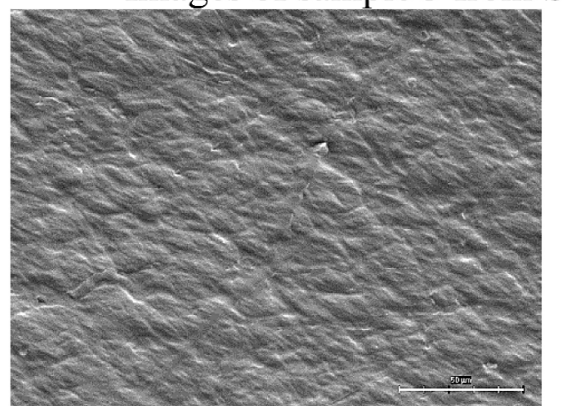

Figure 19. Sample $3 a-1000 \times$

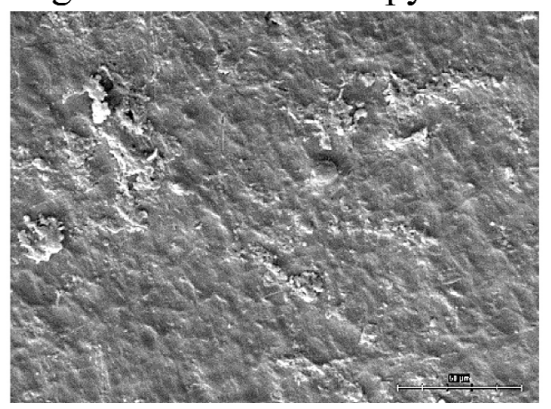

Figure 20. Sample 3b - 1000× 


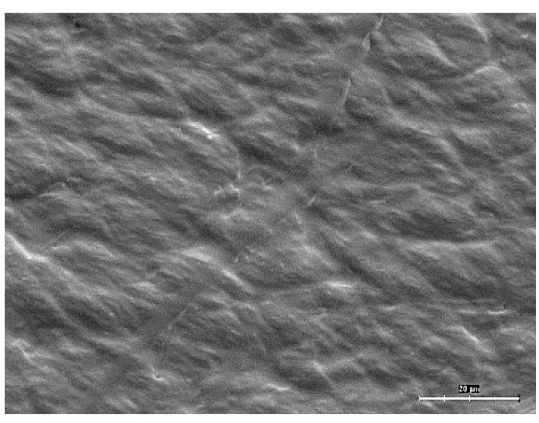

Figure 21. Sample 3a - 2000×

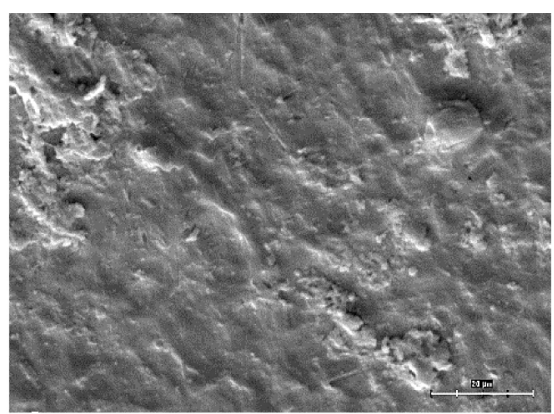

Figure 22. Sample 3b - 2000×

Images of sample 4 from Scanning Electron Microscopy

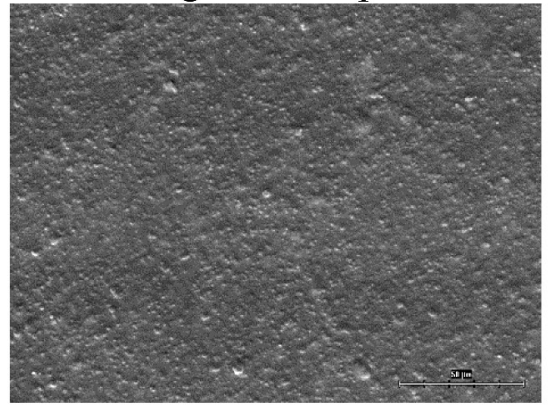

Figure 23. Sample 4a - 1000×

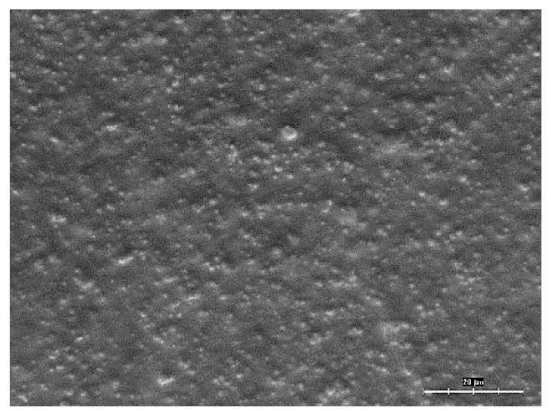

Figure 25. Sample 4a - 2000×

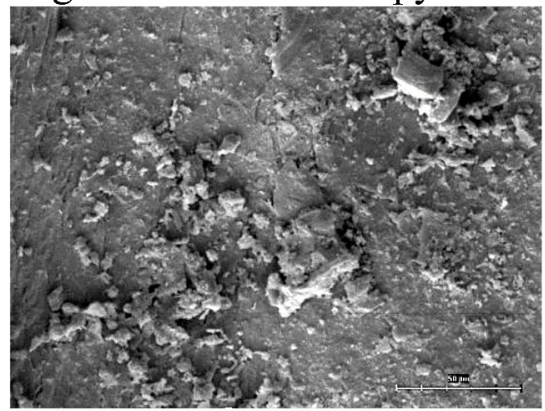

Figure 24. Sample 4b - 1000×

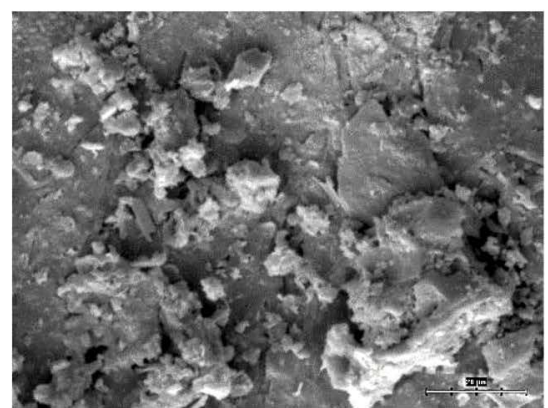

Figure 26. Sample 4b - 2000×

Images of sample 6 from Scanning Electron Microscopy

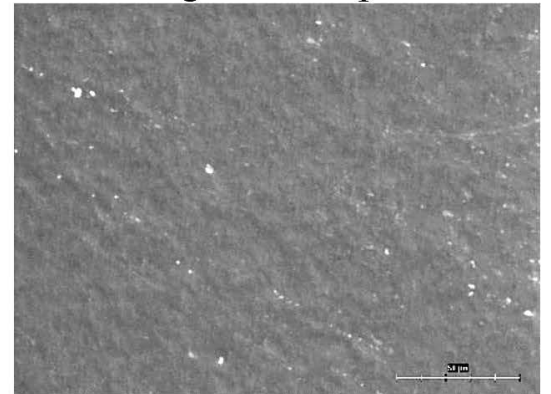

Figure 27. Sample 6a - 1000×

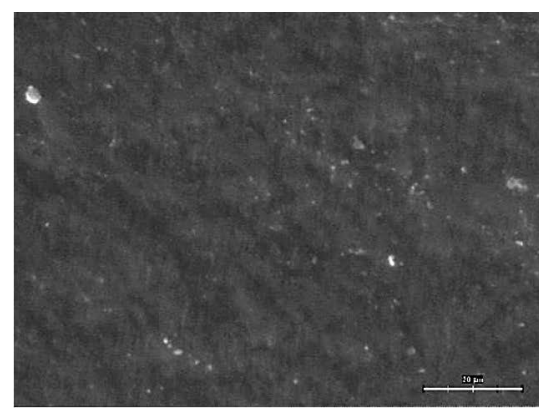

Figure 29. Sample 6a - 2000×

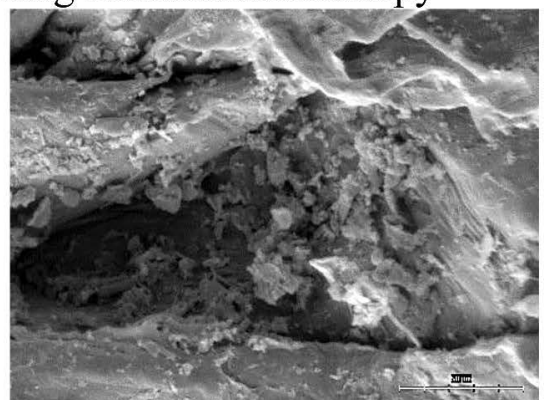

Figure 28. Sample 6b - 1000×

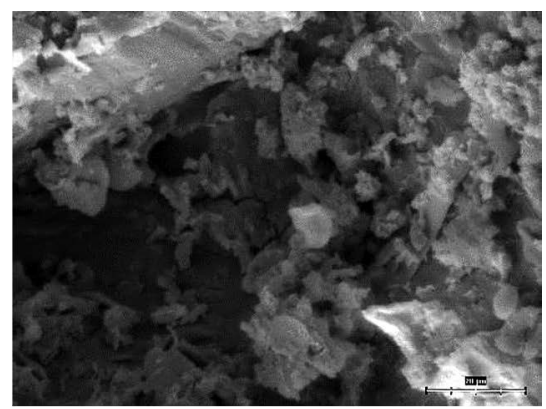

Figure 30. Sample 6b - 2000× 
pared to the composted samples (defined as "(b)") show the smallest difference in case of sample 2. Only slight changes can be observed at sample 3. Sample 1 shows certain erosion of surface as well as sample 4 . Sample 6 significantly degraded as apparent by visual detection. This fact was additionally confirmed by the figures from the SEM analysis (Sample 6b, see Figures 27 and 29).

\section{CONCLUSION}

It can be concluded that plastic bags certified as compostable have degraded in laboratory conditions and their degradation had no impact on the quality and features of compost. Selected samples $(4,6)$ showed significant erosion on surface when subjected to the SEM analysis. Samples labeled (by their producers) as $100 \%$ degradable (samples $1,2,3$ ) that were tested in laboratory conditions did not show any visual signs of degradation and the process of degradation had no impact on the quality and features of compost. Only one of the samples (sample 1) showed certain erosion of surface when submitted for the SEM analysis.

\section{Acknowledgments}

This study was supported by the IGA - Internal Grant Agency Faculty of AgriSciences MENDELU No. IP 5/2016 "The relationship between the bedding and the occurrence of mastitis in dairy cows".

\section{REFERENCES}

1. Adamcová D., Toman F., Vaverková M., Kotovicová J. 2013. The effect of biodegradation/degradation of degradable plastic material on compost quality. Ecological Chemistry and Engineering S. 20 (4), 783-798.

2. Billingham N. C., Bonora M., De Corte D. 2002. Environmental degradable plastics based on oxodegradation of conventional polyolefins in Pro- ceedings of the 7th World Conference on Biodegradable Polymers and Plastics, Pisa, June 4-8.

3. ČSN 465735 Norm "Industrial composts".

4. ČSN EN 14806 Norm "Packaging - Preliminary evaluation of the disintegration of the packaging materials under simulated composting conditions in a laboratory scale test”.

5. ČSN EN ISO 20200 "Plastics - Determination of the degree of disintegration of plastic materials under simulated composting conditions in a laboratory-scale test".

6. Domka L., Malicka A., Jagła K., Kozak A. 2009. Biodegradation of Starch-Modified Foil in Natural Conditions. Polish J. of Environ. Stud. 18 (2), 191-195.

7. Chiellini E., Corti A., Swift G. 2003. Biodegradation of thermally-oxidised, fragmented lowdensity polyethylene. Polymer Degradation and Stability. 81, 341-351.

8. Jakubowicz I., Yarahmadi N., Petersen H. 2006. Evaluation of the rate of abiotic degradation of biodegradable polyethylene in various environments. Polym Degrad Stab. 91, 1556-1562.

9. Kozłowski M. 1998. Fundamental problems of recycling of plastics. Wroclaw Technical University Press, Wrocław.

10. Mudgal S., Lyons L., Bain J., Dias D., Faninger T., Johansson L., Dolley P., Shields L., Bowyer C. 2011. Plastic Waste in the Environment - Revised Final Report for European Commission DG Environment.

11. Pieluchowski J., Puszyński A. 1998. Technology of plastics. WNT.

12. Raninger B., Steiner G., Wales D.M., Hare C.W.J. 2002. Tests on composting of degradable polyethylene in respect to the duality of the end product compost. Microbiology of Composting, Springer.

13. Rojas E., Greene J. 2007. Performance Evaluation of Environmentally Degradable Plastic Packaging and Disposable Food Service Ware - Final Report. $1-70$.

14. Vaverková M., Toman F., Adamcová D., Kotovicová J. 2012. Study of the Biodegrability of Degradable/Biodegradable Plastic Material in a Controlled Composting Environment. Ecological Chemistry and Engineering S. 19 (3), 347-358. 